\title{
Rectal epithelial cell proliferation patterns as predictors of adenomatous colorectal polyp
}

\section{recurrence}

\author{
M Anti, G Marra, F Armelao, A Percesepe, R Ficarelli, G M Ricciuto, A Valenti, \\ G L Rapaccini, I De Vitis, G D’Agostino, S Brighi, F M Vecchio
}

\begin{abstract}
To determine whether proliferative patterns in flat rectal mucosal samples can predict the recurrence of adenomatous colorectal polyps, after polypectomy, biopsy specimens from normal looking rectal mucosa were obtained at endoscopy from 55 patients diagnosed for the first time as having adenomatous colorectal polyps. Epithelial cell proliferation was assessed in biopsy specimens through ${ }^{3} \mathbf{H}$-thymidine autoradiography. After polypectomy, patients were followed for 24 months and underwent complete colonoscopy every 6 months to detect and remove any metachronous lesions. In 40 patients second biopsy specimens were taken during one of the follow up colonoscopies to evaluate the stability of proliferative indices over time. The ratio of labelled (S phase) to total cells (labelling index) for the entire crypt, as well as ratios for each of the five equal compartments into which the crypt had been divided longitudinally, was calculated for each patient. Mean labelling indices for upper crypt compartments 3 and $4+5$ in the 22 patients in whom polyps recurred were significantly higher (respectively $\mathrm{p}<0.05$ and $\mathrm{p}<0.01$ ) than those of the 33 without recurrence suggesting that an upward shift of the crypt's replicative compartment is associated with polyp recurrence. Labelling indices remained essentially unchanged in those patients who underwent biopsy twice. Reproducible kinetic parameters such as these might be useful in planning follow up of patients with adenomatous polyps after polypectomy.
\end{abstract}

(Gut 1993; 34: 525-530)

Departments of Internal Medicine and Pathology, Catholic University, Largo F Vito, 1 - 00168 Rome, Italy $M$ Anti

G Marra

F Armelao

A Percesepe

R Ficarelli

G M Ricciuto

A Valenti

G L Rapaccini

I De Vitis

G D'Agostino

$S$ Brighi

F M Vecchio

Correspondence to:

Dr Anti, Department of

Internal Medicine, Catholic

University of Rome, Largo F

Vito, 1, 00168 Rome, Italy.

Accepted for publication

31 August 1992
It is generally accepted that most colorectal carcinomas arise from adenomatous tissue, ${ }^{12}$ which usually but not always assumes the form of polyps. $^{34}$ Polyp removal is therefore recommended as a way of interrupting the adenomacarcinoma sequence. ${ }^{5}$ Polyps recur, however, in $30-50 \%$ of all polypectomy patients, ${ }^{6-9}$ and they must therefore be followed with regular colonoscopic examinations. The precise level of risk associated with new adenomas that occur after polypectomy has not been fully defined, howlength of adequate surveillance. ${ }^{5} 10$

Numerous clinical, pathological, and biological features of index or baseline (as opposed to recurrent) polyps have been evaluated as potential 'markers' for predicting recurnormal mucosal samples may also provide inforever, and there is still some debate over the rence ${ }^{611-15}$ but examination of histologically mation on the likelihood of recidivism. Proliferative abnormalities in normal looking colorectal mucosa are believed to represent an early phase of colorectal carcinogenesis ${ }^{16}$ and have been found in a number of conditions associated with a high risk for these malignancies. ${ }^{18-27}$ These changes may also precede the development of adenomatous polyps. ${ }^{17212325}$

Using ${ }^{3} \mathrm{H}$-thymidine autoradiography, Deschner, Lipkin, et al ${ }^{19} 2829$ have shown that in high risk subjects, proliferating cells are not confined to the lower two thirds of the colonic crypts, as they are in normal subjects, but are scattered throughout the entire length of the gland. For this reason, most investigators ${ }^{18192122}$ agree that several longitudinal compartments should be defined along each crypt column to provide more precise descriptions of the distribution of labelled or replicating cells. Potten et $a l^{27}{ }^{30}$ have recently described a software package which generates frequency plots of labelling indices against the exact cell position within the crypt. Since the proliferative abnormalities generally affect the entire colonic mucosa in high risk subjects, ${ }^{21} 2231$ reflecting the model of 'field cancerisation' first described by Slaughter $e t a l,{ }^{32}$ most investigators use the proliferative pattern of the more accessible rectal mucosa as an index of the proliferative activity of the colon as a whole. ${ }^{181921223334}$

The purposes of this 2 year prospective study were: (1) to determine whether rectal epithelial cell proliferation evaluated at index polypectomy can be used to predict the risk for adenoma recurrence and (2) to assess the stability of this marker over time.

\section{Patients and methods}

\section{PATIENTS}

Fifty five patients ( 29 men and 26 women aged 23 to 77 years) (mean (SD) $56.2(12.5)$ years) with sporadic adenomatous polyps of the large bowel took part in this study. None had ever been diagnosed as having colorectal polyps before our examination. Patients with hyperplastic polyps only were not accepted for enrollment.

At the beginning of the study, each polyp patient underwent total colonoscopy and a 'clearing' polypectomy to ensure a polyp free colon. Pancolonoscopy was performed between 0800 and 1200 hours after standard preparation with a polyethylene glycol solution taken the evening before. During this examination, three to four samples of flat rectal mucosa were taken from an area $10-15 \mathrm{~cm}$ from the anal verge and 
used for the proliferative studies described below. Repeat colonoscopies were performed every 6 months for the entire 2 year follow up period, and any metachronous adenomas that had occurred were removed. On the basis of these findings, two subgroups were distinguished - a relapsing group, in which recurrence was noted during one or more of the follow up examinations, and a non-relapsing group, in which no recurrences were observed during the entire 24 month study period.

In 40 of the 55 patients, biopsy of the flat mucosa was repeated during one of these subsequent surveillance examinations and the proliferative patterns found in these samples were compared with those of the baseline biopsy samples. The mean interval between baseline and repeat biopsies was $15 \cdot 0$ months $(6$ months in six cases, 12 months in 10,18 months in 22 , and 24 months in two patients). None of the 55 patients was given any type of medical treatment during the study period and all were instructed to continue their normal dietary habits.

A second group fo 28 subjects ( 16 men and 12 women, aged 25 to 80 years (mean (SD) 61.5 $(14 \cdot 2)$ years) were used as controls. These subjects had all undergone colonoscopy for diagnostic purposes. With the exception of an occasional haemorrhoid, findings were negative for all types of colorectal pathology, and none of the control patients or their families had histories of either colorectal malignancy or inflammatory bowel disease. Index biopsy specimens were taken during this colonoscopic examination as described above for the polyp group. There was no colonoscopic follow up of control patients.

\section{EVALUATION OF RECTAL EPITHELIAL CELL PROLIFERATIVE PATTERNS}

Within 15 minutes of removal, biopsy specimens of flat rectal mucosa were washed in saline solution and cut into $1 \mathrm{~mm}$ thick fragments. According to a slightly modified ${ }^{22}$ method described by Deschner and Lipkin, ${ }^{19}{ }^{35}$ the mucosal fragments were then transferred to sterile septum fitted vials containing $2 \mathrm{ml}$ of Eagle's basic salt solution supplemented with $10 \%$ calf serum (GIBCO, Paisley, Scotland) and $5 \mu \mathrm{Ci}$ ${ }^{3} \mathrm{H}$-thymidine/ml (specific activity, $25 \mathrm{Ci} / \mathrm{mmol}$ ) (Amersham, Buckinghamshire, UK). A mixture of $95 \% \mathrm{O}_{2} / 5 \% \mathrm{CO}_{2}$ was injected through the vial's septum until an internal pressure of 3-4 atm was reached, and the vials were incubated at $37^{\circ} \mathrm{C}$ for 1 hour in a shaking bath. After incubation, the specimens were washed with four changes of saline solution at $4^{\circ} \mathrm{C}$, fixed in Bouin solution for 1 hour, transferred to ethanol solutions, and embedded in paraffin.

The paraffin block was cut into $3 \mu \mathrm{m}$ thick sections which were placed on slides. Pooled slides from several patients were dipped in Ilford K5 (Ilford Ltd, Mobberley, Cheshire, England) emulsion and placed inside a light-tight box where they were kept at $4^{\circ} \mathrm{C}$ for 10 days. After exposure, the slides were developed in Ilford Phenprint at $18^{\circ} \mathrm{C}$, fixed in Ilford Hypam fixative, and counterstained with haematoxylin and eosin.

Analysis was confined to those crypts whose entire lengths could be completely visualised and which contained a single layer of cells only. Identification and counts of 'labelled' cells - that is, those in S-phase during the incubation period - was carried out at $\times 1000$ magnification. The dose of tritiated thymidine used here, which is somewhat higher than that used by many other investigators, ${ }^{18} 1921$ produces clear cut labelling of $\mathrm{S}$-phase muclei with numerous black grains against a negligible background. When weaker labelling made grain counts necessary, a cut off of 6 grains or more was used to define labelling.

The total number of cells, as well as the number and the position of labelled cells, was recorded for each crypt column - that is, each side of the length of a crypt. A total labelling index was calculated as the ratio of labelled cell to total cell numbers for each column. In addition, each column was divided into five equal compartments from the base (compartment 1) to the mouth of the gland (compartment 5), and the ratio of labelled to total cells was calculated for each compartment. Since the number of labelled cells in the upper crypts was often quite low, a single labelling index was calculated for compartment $4+5$ (labelling index $4+5$ ) as suggested by other investigators. ${ }^{22}$ This high crypt region generally represents $40 \%$ of the crypt length. In those patients from whom two biopsy specimens had been taken, slides were read by the same examiner. A minimum of 25 different and well oriented columns were considered sufficient to evaluate the proliferative pattern of the epithelial cells; cases with fewer than 25 columns were excluded from the analysis.

\section{STATISTICAL ANALYSIS}

The $\chi^{2}$ test was used to compare the pathological features of the index polyps in relapsing patients with those of patients in whom recurrence was not observed. Group and subgroup means (SEM) were calculated for all of the proliferative data. Since the distribution of ${ }^{3} \mathrm{H}$-thymidine labelling indices was normal, Student's $t$ test for unpaired data was used to compare index values among the groups of subjects studied. Threshold labelling indices above which polyp recurrence was most likely to occur were identified through linear discriminant analysis. Multivariate analysis was also performed to determine which of these proliferative parameters was independently associated with relapse. Student's $t$ test was used to compare mean differences $(\Delta)$ between the first and the second biopsy labelling indices in relapsing and non-relapsing patients. $p$ values of $<0.05$ were considered significant.

\section{Results}

During the 24 month follow up period, 22 (40\%) of the 55 polyp patients developed metachronous polyps. Table I compares the clinical and pathological characteristics of these patients with those of the other $33(60 \%)$ in whom there were no recurrences after the initial polypectomy. Recurrent polyps were noted at the 6 month follow up examination in three patients, at the 12 month examination in eight, at the 18 month visit in nine, and at the final ( 24 month) examination in 
TABLE I Characteristics of 55 patients with adenomatous polyps diagnosed for the first time at the beginning of this study. Patients have been divided according to whether or not metachronous polyps were found during the follow up period

\begin{tabular}{|c|c|c|}
\hline & Non-relapsing & Relapsing \\
\hline No of patients & & \\
\hline $\operatorname{Sex}(\mathbf{M} / \mathbf{F})$ & $17 / 16$ & $12 / 10$ \\
\hline Age (mean (SD)) & $54 \cdot 7(12 \cdot 4)$ & $61 \cdot 2(12 \cdot 1)$ \\
\hline \multicolumn{3}{|l|}{ No of patients with: } \\
\hline $\begin{array}{r}1 \text { polyp } \\
>1 \text { polyp }\end{array}$ & $\begin{array}{l}14 \\
19\end{array}$ & $\begin{array}{l}11 \\
11\end{array}$ \\
\hline \multicolumn{3}{|l|}{ No of patients with: } \\
\hline Largest polyp <1 cm & 15 & 7 \\
\hline Largest polyp $\geq 1 \mathrm{~cm}$ & 18 & 15 \\
\hline \multicolumn{3}{|l|}{ Degree of displasia: } \\
\hline Low grade & 27 & 17 \\
\hline High grade & 6 & 5 \\
\hline \multicolumn{3}{|l|}{ Histotype: } \\
\hline Tubular & 17 & 8 \\
\hline Tubulo-villous & 15 & 12 \\
\hline Villous & 1 & 2 \\
\hline
\end{tabular}

two. None of these patients experienced more than one recurrence during the study period. No significant differences $\left(\chi^{2}\right.$ test) were found between the two subgroups as far as index polyp number, size, histotype, or degree of dysplasia were concerned.

Table II contains the proliferative parameters (group means (SEM) of all patients enrolled in this study - healthy controls and patients with polyps - the latter divided into the two subgroups mentioned above. There was virtually no correlation between these parameters and any of the clinical and histological features of index polyps referred to in Table I (data not shown). Comparison of the polyp group as a whole and the control group showed no significant differences as far as total labelling indices or those for compartments 1,2 , or 3 (the lower $60 \%$ of the crypt) were concerned, although the mean values for the polyp group were consistently higher. The mean labelling index for the upper compartment $(4+5)$ in the polyp group was, however, significantly $(p<0.05)$ higher than that of the controls.

Within the polyp group, there were significantly higher numbers of labelled cells in compartment $3(p<0.05)$ and compartment $4+5$ $(\mathrm{p}<0.01)$ in those patients in whom adenomas recurred compared with those without recurrences. The proliferative pattern of this latter subgroup was quite similar to that of controls, whereas the total labelling index $(p<0.05)$, as well as the indices for compartments $3(p<0.01)$ and $4+5(p<0.01)$, in the relapsing subgroup were all significantly higher than those of controls. The Figure shows the individual labelling indices for compartment 3 and $4+5$ for the-two subgroups of polyp patients. Linear discriminant analysis showed that polyp recurrence within 2 years of index polypectomy was most likely to occur when index labelling indices were greater than $15 \cdot 5$ for compartment 3 or greater than 3.5 for compartment $4+5$. Multivariate analysis showed that the latter index was clearly an independent predictor of relapse while the $p$ value for the compartment 3 labelling index was borderline $(\mathrm{p}=0.057)$.

Table III presents the mucosal proliferation parameters in the 40 polyp patients in whom biopsies for proliferation studies were repeated during one of the follow up colonoscopies. Eighteen of these patients were members of the relapsing subgroup, and 22 of the non-relapsing group. Data from both baseline and follow up specimens are shown separately for the two subgroups. The mean labelling indices did not change significantly over time regardless of whether or not there were recurrences.

\section{Discussion}

The main findings of this study can be summarised as follows: (a) patients with adenomatous colorectal polyps generally showed a significant increase in the cytoproliferative activity of the most superficial portions of the rectal crypts compared with controls; (b) this difference was primarily the result of an appreciable upward shift of replicating cells in patients destined to suffer from recurrent polyps; the proliferative patterns of patients whose polyps did not recur after initial polypectomies were essentially similar to those of controls; (c) the proliferative pattern of flat rectal mucosa did not change appreciably during the follow up period regardless of whether polyps recurred or not.

Previous studies have shown that expansion of the proliferative compartment toward the surface of the colonic gland is a common feature in subjects at high risk for colorectal cancer. ${ }^{18-26}$ The presence of replicative epithelial cells in the upper crypt has classically been shown with ${ }^{3} \mathrm{H}$ thymidine labelling, and more recently by an in vivo bromodeoxyuridine labelling technique. ${ }^{27}$ It is thought to reflect defective cell proliferation control and delayed onset of normal differentia-

TABLE II Proliferative parameters found at index colonoscopy in 55 patients with adenomatous polyps (grouped according to whether or not post-polypectomy recurrence was noted during follow up) and 28 control patients

\begin{tabular}{|c|c|c|c|c|}
\hline & \multirow[b]{2}{*}{ Controls } & \multicolumn{3}{|c|}{ Patients with polyps (follow up, 24 months) } \\
\hline & & Total & Non-relapsing & Relapsing \\
\hline No of patients & 28 & 55 & 33 & 22 \\
\hline $\begin{array}{l}\text { Age (mean }(\mathrm{SD})) \\
\text { Columns assayed (no) }\end{array}$ & $\begin{array}{l}61 \cdot 5(14 \cdot 2) \\
778\end{array}$ & $\begin{array}{l}56 \cdot 2(12 \cdot 5) \\
1702\end{array}$ & $\begin{array}{l}54 \cdot 7(12 \cdot 4) \\
1016\end{array}$ & 686 \\
\hline Columns per patient (no) & $27 \cdot 8$ & $30 \cdot 9$ & $30 \cdot 8$ & $31 \cdot 2$ \\
\hline Cells per column (mean (SEM)) & $57.5(1.61)$ & $54 \cdot 7(1 \cdot 67)$ & $54.9(2 \cdot 01)$ & $54 \cdot 4(1 \cdot 48)$ \\
\hline Cells counted (no) & 44735 & 93096 & 55778 & 37318 \\
\hline Labelled cells (no) & 4378 & 10981 & 6053 & 4928 \\
\hline Total labelling index (LI) (mean (SEM)) & $9 \cdot 5(0 \cdot 86)$ & $11 \cdot 1(0 \cdot 58)$ & $10 \cdot 4(0.62)$ & $12.7(0.87) \#$ \\
\hline \multicolumn{5}{|l|}{ Crypt compartment LI (mean (SEM)): } \\
\hline Compartment 1 & $13.05(1 \cdot 39)$ & $13 \cdot 7(1 \cdot 01)$ & $14 \cdot 7(0 \cdot 98)$ & $12 \cdot 5(1 \cdot 27)$ \\
\hline Compartment 2 & $19.9(1 \cdot 48)$ & $21 \cdot 6(1 \cdot 21)$ & $20 \cdot 8(1 \cdot 20)$ & $23 \cdot 8(2 \cdot 07)$ \\
\hline Compartment 3 & $11 \cdot 05(1 \cdot 50)$ & $14 \cdot 4(1 \cdot 19)$ & $12 \cdot 4(1 \cdot 20)$ & $18.6(1.56)^{\star} \# \#$ \\
\hline Compartment $4+5$ & $1.6(0 \cdot 40)$ & $3 \cdot 1(0.41) \oint$ & $2 \cdot 2(0 \cdot 37)$ & 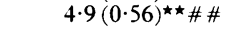 \\
\hline
\end{tabular}

Unpaired $t$ test: $\oint \mathrm{p}<0.05 v$ controls; ${ }^{\star} \mathrm{p}<0.05 v$ non-relapsing; ${ }^{\star \star} \mathrm{p}<0.01 v$ non-relapsing; \# $\mathrm{p}<0.05 v$ controls; \# \# $\mathrm{p}<0.01 v$ controls. 


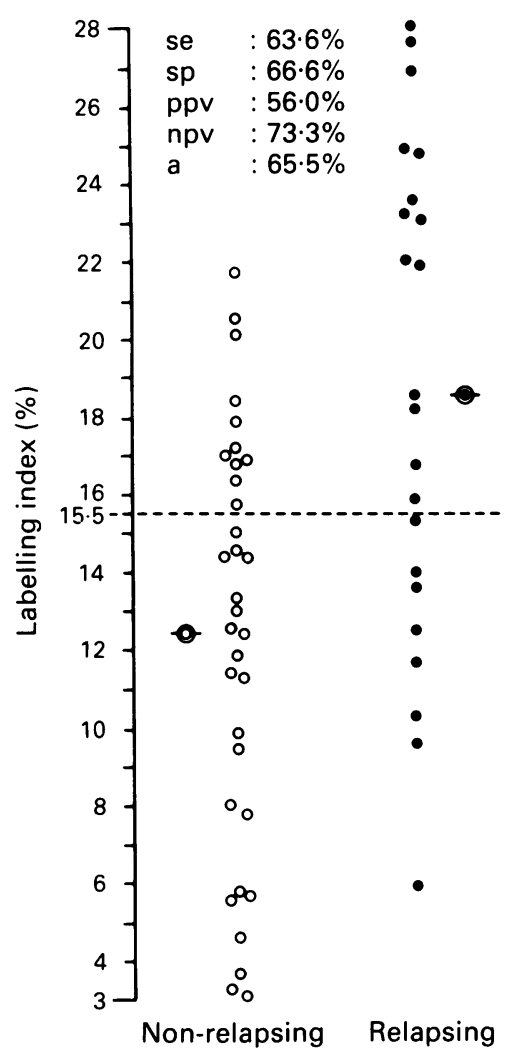

$B$

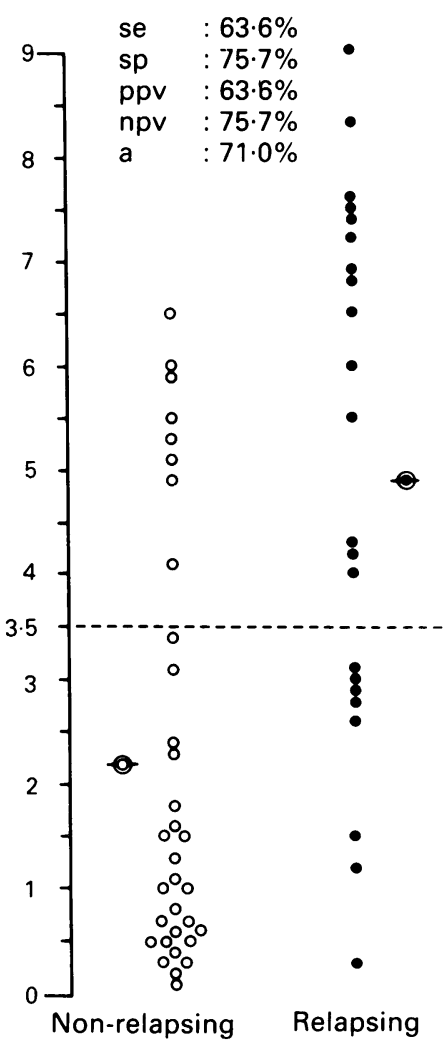

Individual labelling indices for colonic crypt compartments $3(A)$ and $4+5(B)$ in polyp patients from the non-relapsing and relapsing subgroups. (-O)-) and (-) represent group means. The broken line represents the threshold represents the threshold
values (calculated with linear discriminant analysis) above which recurrence was most likely to occur. The boxes show sensitivity (se), specificity (sp), positive predictive values ( $p p v)$, negative predictive values (npv), and predictive accuracy (a) of thresholds.

tion. ${ }^{1628}$ These replicative cells are extremely sensitive to the effects of intraluminal carcinogens, and their exposure to these substances is greater when they are located in the upper crypt..$^{29}$ For this reason, the pattern of the proliferative cells in this area of the colorectal crypt is considered to be the most discriminatory index of a subject's level of risk for colorectal cancer. ${ }^{22}$

Most investigators ${ }^{18} 1921223334$ use the proliferative pattern of the rectal mucosa as a reliable index of the cytoproliferative activity of the entire colonic mucosa. Several studies have shown that mucosal cell proliferation is uniform throughout the various segments of the colon in normal subjects, ${ }^{21} 22$ in those with adenomatous polyps or colon cancer, ${ }^{21}$ and in those with hereditary risk factors for colon malignancy. ${ }^{31}$ However, Potten et $a l^{27}{ }^{30}$ have recently reported that in vivo bromodeoxyuridine labelling indices for the rectal mucosa were lower than those for the rest of the colon, which were fairly homogeneous. The mean rectal labelling index reported by these investigators was, in fact, lower than that found in any of the groups of our study.

Potten et al are the first to point out that their findings are based entirely on the study of patients with colorectal cancer and, although the specimens used were taken at least $5 \mathrm{~cm}$ from the primary carcinoma and did not show any unusual histological features, there may be differences with respect to the colonic mucosa of patients without carcinoma. In their most recent study $^{27}$ they compared these distant from the tumour with those from histologically normal samples taken within a $1 \mathrm{~cm}$ radius of the tumour and found that regardless of the colonic segment being considered, the proliferative activity in tumour adjacent tissues was generally dampened with respect to that of the more distant specimens. If, as these authors postulate ${ }^{27}$ the tumour exerts some type of inhibitory effect on the proliferation of the cells surrounding it, it is possible that the lower labelling index reported for the rectal segment is at least party related to a wider - that is, extending beyond a $5 \mathrm{~cm}$ radius zone of inhibition produced by rectal tumours with respect to those arising in other colonic segments.

It is, however, quite possible that the proliferative activity of the rectum is, indeed, lower than that of the rest of the colon. Other investigators, using a microdissection technique on biopsy specimens, ${ }^{36}$ have reported less proliferative activity in the rectum of patients without colon cancer. With regard to the validity of rectal cell proliferation as an index of that of the colon as a whole, the in vitro results of Terpstra et al are significant. ${ }^{21}$ While these authors also noted a slight decrease in the proliferative activity of the distal colon, they found that this difference remained constant regardless of the risk status of the subject (normal controls, small or large adenomas, colon cancer)

Our data confirm an upward shift of the proliferative zone in the patients with adenomatous colorectal polyps (which are themselves associated with an increased tendency to develop colon cancer). This shift was not observed in the normal controls with no identifiable risk factors for these malignancies.

Within the polyp group, labelling pattern differences also emerged between the subgroup

TABLE III Proliferative findings from the non-relapsing $($ no $=22)$ and relapsing $(n o=18)$ polyp patients evaluated twice, at index colonoscopy and again during one of the follow up examinations

\begin{tabular}{|c|c|c|c|c|c|c|}
\hline & \multicolumn{3}{|l|}{ Non-relapsing } & \multicolumn{3}{|l|}{ Relapsing } \\
\hline & Ist evaluation & 2nd evaluation & Change $e^{\star}$ & Ist evaluation & 2nd evaluation & Change ${ }^{\star}$ \\
\hline \multirow{6}{*}{$\begin{array}{l}\text { Columns assayed (no) } \\
\text { Columns per patient (no) } \\
\text { Cells counted (no) } \\
\text { Labelled cells (no) } \\
\text { Cells per column (mean (SEM)) } \\
\text { Total labelling index (LI) (mean } \\
\quad(\text { SEM }))\end{array}$} & 690 & 643 & & 546 & 605 & \\
\hline & $31 \cdot 4$ & $29 \cdot 25$ & & $30 \cdot 3$ & $33 \cdot 6$ & \\
\hline & 36366 & 34701 & & 29996 & 32192 & \\
\hline & 3460 & 3420 & & 3352 & 4370 & \\
\hline & $54 \cdot 7(2 \cdot 12)$ & $53 \cdot 8(2 \cdot 18)$ & $1 \cdot 0(1 \cdot 58)$ & $54 \cdot 4(1 \cdot 73)$ & $53 \cdot 2(1 \cdot 87)$ & $1 \cdot 2(1 \cdot 78)$ \\
\hline & $10 \cdot 2(0 \cdot 72)$ & $10.4(0.69)$ & $-0.20(0.41)$ & $12 \cdot 4(0.91)$ & $12 \cdot 8(0 \cdot 77)$ & $-0.36(0.45)$ \\
\hline \multicolumn{7}{|l|}{$\begin{array}{l}\text { Crypt compartment LI (mean } \\
(\text { SEM)) }\end{array}$} \\
\hline Compartment 1 & $13 \cdot 1(0 \cdot 89)$ & $14.3(0.98)$ & $-1 \cdot 16(0.63)$ & $12 \cdot 9(1 \cdot 22)$ & $13 \cdot 6(11 \cdot 1)$ & $-0.73(0.86)$ \\
\hline Compartment 2 & $20.4(1.33)$ & $20 \cdot 3(1 \cdot 21)$ & $0.07(0.50)$ & $24 \cdot 5(1 \cdot 75)$ & $25 \cdot 3(1.91)$ & $-0.83(0.73)$ \\
\hline Compartment 3 & $11.5(1.29)$ & $11 \cdot 1(1 \cdot 13)$ & $0.43(0.41)$ & $15 \cdot 7(1.54)$ & $16 \cdot 3(1 \cdot 58)$ & $-0.65(0.84)$ \\
\hline Compartment $4+5$ & $2.0(0.35)$ & $2 \cdot 15(0 \cdot 36)$ & $-0.13(0.22)$ & $4.6(0.53)$ & $5.0(0.56)$ & $-0.40(0.29)$ \\
\hline
\end{tabular}

$\star$ Represents subgroup mean (SEM) change between first and second evaluation; all were non-significant $(t$ test) 
of patients in whom polyps recurred and those in whom the colon remained polyp free during the follow up period. The former subgroup showed the same upward shift observed for the polyp group as a whole, but the differences, with respect to normal controls were even more noticeable, involving significant increases not only in the labelling indices of compartments 3 and $4+5$, but also in the total labelling index. In contrast, the subgroup in whom no recurrences were observed showed mean labelling indices that were not significantly different from those of controls.

Linear discriminant analysis showed that polyp recurrence could be predicted with $71 \%$ accuracy when the compartment $4+5$ labelling index exceeded $3 \cdot 5$. The prognostic value of this parameter might have been higher if the follow up of our patients had been longer, since some of the patients with high upper crypt labelling indices who did not relapse might have experienced later recurrences. But regardless of the precise predictive value of this threshold, our findings show clearly that patients destined to suffer recurrence presented a persistent upward shift in the proliferative pattern which could be detected before the relapse occurred. Similar differences between relapsing and non-relapsing polyp patients ahve already emerged from previous studies, ${ }^{23} 37$ although other investigators have found no significant differences whatsoever. ${ }^{25}$ Future advances in technology may disclose other, more sensitive markers of cell proliferation whose predictive accuracy is greater.

The heterogeneity of proliferative patterns found within the high risk population used for this study is not surprising. Diversity has also been reported within groups with other high risk conditions for colorectal cancer. ${ }^{18193037-39}$ The difference noted within our polyp group may be explained in a number of ways. Firstly, patients with sporadic adenomatous colorectal polyps are known to have a higher risk of developing colorectal cancer, but the possible modulation of this risk by hereditary or environmental factors will naturally vary from subject to subject. An inherited susceptibility has recently been reported in a subgroup of patients with common - that is, apparently sporadic - adenomatous polyps. ${ }^{+0}$ Modulation of proliferative anomalies by environmental factors - for example the intensity or length of exposure to protective substances in the diet, or both, has also been shown by a number of studies. ${ }^{33+1+2}$ One example is our recent observation of changes in the proliferative patterns of the rectal mucosa induced by omega- 3 fatty acid supplementation in patients with adenomatous polyps. ${ }^{4}$

On the other hand, this heterogeneity between risk groups might reflect the existence of constitutionally distinct subgroups within a population that has different forms of susceptibility to adenoma development: one with generalised and noticeable proliferative anomalies throughout the entire colonic epithelium that produce an increase tendency toward recidivism, and a second, less recidivant subgroup in whom polyp development is not preceded by the generalised pattern of hyperproliferation seen in the first group but by other types of alterations as yet unidentified. One hypothesis, which was first advanced by Deschner in $1975^{29}$ and has recently been reproposed by Rozen, ${ }^{++}$is that the same type of proliferative anomalies are also present in the second subgroup but in a localised rather than diffuse form. If the latter were true, random sampling of the normal mucosa would be less reliable as a means of ascertaining risk. However, the uniformity of mucosal cell proliferative patterns in the various colonic segments that was discussed earlier would shed some degree of doubt on this possibility. ${ }^{21} 22273031$

Finally, our data donfirm the longitudinal stability of the kinetic markers (both total labelling index and compartmental distribution of labelled cells) over time. This finding is in agreement with those of Lynch et al ${ }^{39}$ Furthermore, in dietary trials aimed at reducing the risk of colon cancer in which these parameters were repeatedly evaluated, the same stability has been noted in control patients. ${ }^{42+345+6}$ If more extensive studies confirm our belief that markers of proliferative activity are reliable predictors of polyp recurrence, the initial kinetic pattern can be used to individualise follow up protocols for polypectomy patients, eliminating unnecessary colonoscopy for those who are unlikely to suffer recurrence and increasing surveillance in those with recidivant tendencies.

The authors are grateful for the statistical assistance of Dr Filippo Crea, the technical assistance of Sandro Rinelli, and the editorial aid of Marian Kent.

The findings presented here have been partially published in abstract form in Gut 1992; 33: Supplement 1 .

1 Muto T, Bussey HJR, Morson BC. The evolution of cancer of the colon and rectum. Cancer 1975; 36: 2251-79.

2 Fenoglio-Preiser CM, Hatter RV. Colorectal polyps: pathologic diagnosis and clinical significance. Cancer 1985; 35 322-44.

3 Jass JR. Do all colorectal carcinomas arise in preexisting adenomas? World f Surg 1989; 13: 45-51.

4 Bedenne L, Faivre J, Boutron MC, Piard F, Cauvin JM, Hillon $P$. Adenoma-carcinoma sequence of "de novo carcinogenesis? Cancer 1992; 69: 883-8.

5 Winawer SJ, Schottenfeld D, Flehinger BJ. Colorectal cancer screening. $\mathcal{F}$ Natl Cancer Inst 1991; 83: 243-53.

6 Neugut AI, Johnsen CM, Forde KA, Treat MR. Recurrence rates for colorectal polyps. Cancer 1985; 55: 1586-9.

7 Macrae FA, Williams CB. A prospective colonoscopic follow up study of 500 adenoma patients with multivariate analysis to predict risk of subsequent colorectal tumors. Gastroto predict risk of subseque
enterology $1982 ; 82: 1122$.

8 Waye JD, Braunfeld SF. Surveillance intervals after colonoscopic polypectomy. Endoscopy 1982; 14: 79-81.

9 Matek W, Guggenmoos-Holzmann I, Demling L. Follow up of patients with colorectal adenomas. Endoscopy 1985; 17 : $175-81$

10 Spiro HM. Surveillance for colonic polyps. Mt Sinai $7 \mathrm{Med}$ 1988; 55: 251-6.

1 Atkin WS, Morson BC, Cuzick J. Long-term risk of colorecta cancer after excision of rectosigmoid adenomas. $N$ Engl 7 Med 1992; 326: 658-62.

12 Nava H, Carlsson G, Petrelli NJ, Herrera L, Mittelmann A. Follow up colonoscopy in patients with colorectal adenomatous polyps. Dis Colon Rectum 1987; 30: 465

13 Grossman S, Milos ML, Tekawa IS, Jewell NP. Colonoscopic screening of persons with suspected risk factors for colon cancer: II. Past history of colorectal neoplasms. Gastrocancer: II. Past history of

14 Reinhart SE, Van Stolk RU, Achkar E. Identification of high risk patients with colorectal adenomas. 5th International Symposium on Colorectal Cancer, Turin 1991 (abstract).

15 Griffioen G, Bosman FT, Verspaget HW, Sies KFM Biemond I, Lamers CBHW. Comparative evaluation of carcinoembryonic antigen, secretory component and mucin in index and metachronous adenomas of the colorectum Gastroenterology 1991; 101: 919-26.

16 Lipkin M. Biomarkers of increased susceptibility to gastrointestinal cancer: new application to studies of cancer prevention in human subjects. Cancer Res 1988; 48: 235 +5

17 Fearon ER, Vogelstein B. A genetic model of colorectal tumorigenesis. Cell 1990; 61: 759-67.

18 Deschner EE, Goldbold J, Lynch HT. Rectal epithelial cell proliferation in a group of young adults. Influence of age and genetic risk for colon cancer. Cancer 1988; 61: 2286-90. 
19 Lipkin M, Blattner WE, Fraumeni JF, Lynch HT, Deschner $\mathrm{EE}$, Winawer SJ. Tritiated thymidine $(\phi \mathrm{p} \phi \mathrm{h})$ labeling
distribution as a marker for hereditary predisposition to distribution as a marker for hereditary predis
colon cancer. Cancer Res 1983; 43: 1899-904.

20 Lipkin M, Blattner WE, Gardner EJ, Burt RW, Lynch HT, Deschner EE, et al. Classification and risk assessment of individual with familial polyposis and familial non-polyposis colon cancer from ${ }^{3} \mathrm{H}$ dThd-labeling patterns in colonic epithelial cells. Cancer Res 1984; 44: 4201-7.

21 Terpstra OT, van Blankenstein $M$, Dees J, Eiler GAM. Abnormal pattern of cell proliferation in the entire colonic mucosa of patients with colon adenoma or cancer. Gastroenterology 1987; 92: 704-8.

22 Ponz de Leon M, Roncucci L, Di Donato P, Tassi L, Smerieri $\mathrm{O}$, Amorico MG, Malagoli G, et al. Pattern of epithelial cell proliferation in colorectal mucosa of normal subjects and of proliferation in colorectal mucosa of normal subjects and of patients with adenomatous polyps

23 Risio M, Lipkin M, Candelaresi GL, Bertone A, Coverlizza S, Rossini FP. Correlations between rectal mucosa cell proliferation and the clinical and pathological features of nonfamilial neoplasia of the large intestine. Cancer Res 1991; 51: 1917-21.

24 Paganelli GM, Biasco G, Santucci R, Brandi G, Lalli AA, Miglioli M, et al. Rectal proliferation and colorectal cancer risk level in patients with non familial adenomatous polyps of the large bowel. Cancer 1991; 68: 2451-4.

25 Roncucci L, Scalmati A, Ponz de Leon M. Pattern of cell kinetics in colorectal mucosa of patients with different types of adenomatous polyps of the large bowel. Cancer 1991; 68: 873-8.

26 Biasco G, Paganelli GM, Miglioli M, Brillanti S, Di Febo G, Gizzi G, et al. Rectal cell proliferation and colon cancer risk Gizzi G, et al. Rectal cell proliferation and colon

27 Potten CS, Kellett M, Rew DA, Roberts SA. Proliferation in human gastrointestinal epithelium using bromodeoxyuridine in vivo: data for different sites, proximity to a tumor, and polyposis coli. Gut 1992; 33: 524-9.

28 Lipkin M. Phase 1 and phase 2 proliferative lesions of colonic epithelial cells in diseases leading to colonic cancer. Cancer 1974; 34: 878-88.

29 Deschner EE, Lipkin M. Proliferative patterns in colonic mucosa in familial polyposis. Cancer 1975 ; 35: 413-8.

30 Potten CS, Kellett M, Roberts SA, Rew DA, Wilson GD. Measurement of in vivo proliferation in human colorectal mucosa using bromodeoxyuridine. Gut 1992; 33: 71-8.

31 Cats A, de Vries EGE, Zwart N, Mulder NH, Sluiter WJ, Hardonk MJ, et al. Epithelial proliferation in different segments of the colon in hereditary nonpolyposis colon cancer (HNPCC) Gastroenterology 1992; 102: A 348 .

32 Slaughter DP, Southwick HW, Smejkal W. Field cancerization in oral stratified squamous epithelium: clinical implications of multicentric origin. Cancer 1953; 5: 963-8.
33 Lipkin M, Newmark H. Effect of added dietary calcium on colonic epithelial cell proliferation in subjects at high risk fo

34 Rozen P, Fireman Z, Fine M, Wax Y, Ron E. Oral calcium suppresses increased rectal epithelial proliferation of persons at risk of colorectal cancer. Gut 1989; 30: 650-5

35 Deschner EE, Lipkin M, Solomon C. Studies of human recta epithelial cells in vitro. II ${ }^{3} \mathrm{H}$-Thymidine incorporation into polyps and adjacent mucosa. I Natl Cancer Inst 1966; 36 : 849-57.

36 Goodlad RA, Levi S, Lee CY, Mandir N, Hodgson H, Wright NA. Morphometry and cell proliferation in endoscopic biopsies: evaluation of a technique. Gastroenterology 1991; 101: $1235-41$.

37 Scalmati A, Roncucci L, Ghidini G, Biasco G, Ponz de Leon $M$. Epithelial cell kinetics in the remaining colorectal mucosa after surgery for cancer of the large bowel. Cancer mucosa after surgery for

38 Rozen P, Fireman Z, Fine N, Chetrit A, Lubin F. Rectal epithelial proliferation characteristies of first degree relatives of sporadic colon cancer patients. Cancer Lett 1990; 51 : 127 32.

39 Lynch PM, Wargowich MK, Lynch HT, Palmer C, Lanspa S Drouhard $\mathrm{T}$, et al. A follow up study of colonic epithelia proliferation as a biomarker in a native American family with hereditary non polyposis colon cancer. $\mathcal{F}$ Natl Cancer Inst 1991; 83: $951-4$.

40 Cannon-Albright LA, Skolnik MH, Bishop DT, Lee RG, Burt $\mathrm{RW}$. Common inheritance of susceptibility to colonic adenomatous polyps and associated colorectal cancers. $N E n g l$ matous polyps and associat

41 Alberts DS, Einspahr J, Rees-Mc Gee S, Ramanujam P Bulle MK, Clark L, et al. Effects of dietary wheat bran fiber on rectal epithelial cell proliferation in patients with resection rectal epithelial cell proliferation in patients with resection
for colorectal cancers. F Natl Cancer Inst 1990; 82: 1280-5.

42 Paganelli GM, Biasco G, Brandi G, Santucci R, Gizzi G Villani V, et al. Effect of vitamin A, C, and E supplementation on rectal cell proliferation in patients with colorectal adenomas. F Natl Cancer Inst 1992; 84: 47-51.

43 Anti M, Marra G, Armelao F, Bartoli GM, Ficarelli R Percesepe A, et al. Effect of omega-3 fatty acids on recta mucosal cell proliferation in subjects at risk for colon cancer. Gastroenterology 1992; 103: 883-91.

44 Rozen P, Fireman Z, Fuie N, Chetrit A, Zajicek G. Recta epithelial proliferation in persons post sporadic colorectal epithelial proliferation in persons post
neoplasia. Cancer Lett 1991; 59: 1-8.

45 Gregoire RC, Stern HS, Yeung KS, Stadler Y, Langley S, Furrer $R$, et al. Effect of calcium supplementation on Furrer $\mathrm{R}$, et al. Effect of calcium supplementation on mucosal cell proliferation in

46 Kashtan H, Gregoire RC, Bruce WR, Hay K, Stern HS. Effec of sodium sulphate on fecal $\mathrm{ph}$ and proliferation of colonic mucosa in patients at high risk for colon cancer. $7 \mathrm{Nat}$ Cancer Inst 1990; 82: 950-2. 